\title{
A Proposed Model for Measuring the Performance of Smart Public Parks
}

\author{
Eslam N. Elsayed ${ }^{1}$ and Ahmed N. Ashrry ${ }^{2}$ \\ ${ }^{1}$ Associate Prof. in Department of Architecture Eng., Shoubra Faculty of Eng., Benha University, \\ Cairo, Egypt. \\ (islam.alsayed@feng.bu.edu.eg) \\ ${ }^{2}$ Ph.D. Candidate, Department of Architecture Eng., Shoubra Faculty of Eng., Benha University,
}

\begin{abstract}
Public parks are one of the most important uses of land in cities, because they are green spaces that contribute to purifying the urban environment from carbon emissions and air pollution ratios. They also contribute greatly, including their recreational activities, to the psychological and physical satisfaction of their visitors. Technologies development; a new concept has emerged called Smart Parks that depend on providing energy and are part of the smart city system. Through the research, a deductive approach was followed through an analysis of global and regional models of smart parks, with the aim of extracting and defining performance measurement criteria to integrate them with the consistent design principles of smart parks.

The study set up a proposed model that can be applied to measure the performance of smart parks and the performance of existing traditional parks to support their transformation into smart parks. The model included (8) main criteria, (25) sub criteria, (84) key performance measurement indicators (KPIs). The researcher applied this model to "Al-Azhar Park" and identified indicators that need to be assessed to turn it to a smart park.
\end{abstract}

Keywords: smart park; smart governance; key performance measurement indicators (KPIs); smart environment; landscape elements.

\section{Introduction}

Parks are an essential part of urban life. Technology is constantly changing and developing with tremendous speed in every aspect of our lives, however it is barely used in designing these green areas that provide humanity with great services.

Public parks are considered the lungs of cities and the barrier that protects them from the factors which are affecting human life. Parks present alot of supports to our life such as cleaning the air, reducing the risks of air pollution, tempering the atmosphere, and mitigating from the sun's heat and providing an atmosphere of moisture, psychological satisfaction of the population hence providing a higher quality of living which helps human to increase the productive capacity of workers .

Public parks differ in terms of area, design principles, and landscape elements according to the different function performed by the park, such as zoos, botanical gardens, picnic parks ... As well as the principles for designing public parks differ according to the environmental aspect of each city, as well as differing from country to another. While we find that Egypt allocates 1 acre / 1000 people in public parks we find that, in return, the United States of America allocate 5 acres / 1000 people in [1]. So, Luskin Innovation Center (UCLA) which seeks to solve environmental challenges launched a new concept for the park called "SMART PARKS". This definition is a new addition to parks that use technology (environmental, digital, and materials) to achieve a series of values; equitable access, community fit, enhanced health, safety, resilience, water and energy efficiency, and effective operations and maintenance [2].

Recently, the concept of smart cities has emerged as one of the modern and promising directions in the planning of urban societies and is governed by many dimensions such as smart governance, smart economy, smart mobility, smart environment, smart living, and most importantly smart people in spite of cultural and civilizational identities that are the basic pillars that are indispensable for any society, so they distinguish it from others.

\section{Problem}

The problem is:

- Defining the basic criteria for smart parks and this has resulted in the inability to measure their 
performance, even though smart parks are one of the most important components of smart cities in the modern era.

- The inability to measure the performance of traditional public parks previously established to turn them into smart parks.

\section{Objectives}

The research aims to:

- produce a model for measuring the performance of smart parks based on a set of ruling criteria that include a set of standard indicators, based on the criteria of smart cities .

- evaluate current smart parks and measure the performance of traditional parks to turn them into smart public parks. The research methodology is based on:

- Inductive approach: By identifying the difference between traditional parks and smart parks, the determinants of public parks, the theoretical foundations for the design of public parks and smart public parks and the different criteria and foundations that would govern smart parks.

- Deductive approach: by analyzing some of the global and regional experiences of smart parks to extract the criteria and indicators on which the proposed model would be based on.

\section{Theoretical Studies}

\subsection{The difference between traditional public} parks and smart parks

The parks are green areas that are included in lands that are designated for recreational functions; that do not contain buildings, have different uses, contain greenery, water and vast lands. On the other hand, the parks can be considered to be an area that include various facilities to spend leisure time, and used as separate shelters such as mobile campsites or simple accommodations to spend hiking time, or amusement areas equipped with various playgrounds or activities. There are regional parks that have areas that are between the urban green areas and national parks, and include rural areas or a forest so that their areas are subject to freedom of organization and aim to preserve natural parks [1].

Smart Parks are defined as parks that use technology to reflect and fit well into their socio-physical surroundings and are easily accessible, resilient to climate change. They are also water and energy efficient, easy to maintain, and help promote the health and safety of communities. Also, technological innovations can improve park performance and reduce long-term costs [2].

\subsection{The determinants of public parks}

\subsubsection{Natural determinants}

Climatic factors (temperature, wind, amount of rain), the topography of the land on which the park is located, soil quality and availability of water as follows [3]:

- Climatic factors: It is one of the most important factors in the success of parks. The lack of suitable climate and environment leads to the unsuccessful cultivation of many plants, that would often succeed in other regions with a suitable climate.

- Topography: It affects the design of parks. This effect appears in the style of designing parks and how a human will feel towards the space. The topography can be used to improve the climate of different spaces. However, in this particular environment, surface water drainage remains a problem facing the site's geography.

- Soil fertility: It is an important factor for establishing parks, as good fertile soil can cause diversity in cultivating various plants, while the lack of good agricultural soil causes the need to resort to fertilizers of all kinds to improve the properties of the soil in order to become suitable for cultivation, which henceforth will increase construction costs.

\subsubsection{Unnatural determinants}

It includes all human factors, including social factors, construction costs, periodic maintenance, and the expertise and creativity of the urban designer.

\subsection{Governing standards for smart park design 2.3.1 Value criteria for smart parks}

There are eight value criteria by which the performance of smart parks can be measured or achieved. These standards can be used to measure the performance of public parks and see their ability to be converted into smart parks or used to measure the performance of smart parks [2]. These criteria have a set of key indicators that dictate the standards. Many of the benefits of the criteria affect and overlap with one another, as shown:

Community fit: A smart park creatively utilizes and reflects its physical, ecological, social, and cultural surroundings. Parks that are integrated into their communities can encourage and improve social interactions and social bonding [4].

Access: A smart park is centrally located, easily accessible and psychologically attractive to a community member. People can only benefit from parks if they can reach them, as access may be limited due to geographic barriers, highways and other infrastructure that can obstruct the path to a park [5].

Resilience: A smart park must be resilient to 
changes that may result from development, climate change, demographic change, or other forces. Parks must prepare for environmental challenges that range from rising temperatures to unpredictable precipitation. Urban parks can play an important role in helping cities mitigate and adapt to climate change. Water: A smart park utilizes strategies to conserve and reuse water resources. Parks can incorporate infrastructure to treat city wastewater and handle storm water. Water, for irrigation and water features like fountains or splash pads, is one of the largest operating costs for many parks; thus, water conservation can be a vital strategy for parks with constrained resources[6].

Health: A smart Park facilitates healthy activities and promotes community wellness. Parks can improve community health by providing spaces that encourage increased physical activity and improve mental health. Parks can also be considered therapeutic and will result in the overall improved wellbeing.

Energy: A smart park uses strategies to conserve energy resources and promotes clean energy generation. Parks also can generate their own energy by installing green technologies like solar panels. Another way that smart parks preserve energy, is by reducing the need for air conditioning due to the fact that parks contain a lot of green areas, this therefore results in the improvement of the atmospheric conditions and temperature.

Operations \& Maintenance: A smart park harnesses technology for streamlined and efficient operations and maintenance practices.

Safety: A smart park provides a safe, secure, and comfortable environment for visitors. We can create safe parks by increasing use of technology, such as; using cameras, motion sensors and biometric passwords, improving lighting, and maintaining park safe facilities; including fences and walls. The Safety criterion is closely related to the Operations and Maintenance criteria because poorly maintained facilities are often perceived as less safe.

To achieve the general criteria for smart parks, digital technologies must be used in each landscape element and inside public spaces designed for activities. Here are some digital technologies and possible applications that can be used as an efficient way to govern and achieve all the value criteria of smart parks.

\subsubsection{Digital technologies and application}

Digital technologies and applications that collect and organize data can be used to capitalize park access, safety, programming, operations, and interactions between park managers and visitors. There are four digital technologies, as shown:

- Wi-Fi allows personal electronic devices to connect to the Internet using a wireless connection. Park visitors may use it to help plan activities or use it to create and capture digital content such as photos and videos. Visitors can make calls when cellular networks are not available maintain and ensuring their safety. Park managers can use it to access any services to upload or download data and information.

- Geographic information systems (GIS) uses digital software to store, manipulate, analyze, and present geographical data [7]. It can help determine the roads and parking availability and it can also be used to monitor changes in crime rates at the area surrounding the park, ensuring safety for all visitors. Managers can use GIS to monitor weather, and topographic data which will make it easier to select the most appropriate landscaping to face and reduce climate change. It can be paired with soil fertility and atmospheric requirements to manage how to use water more efficiently in parks.[8].

- Applications softwares (apps) are softwares that can run on computers, tablets, smartphones, or other electronic devices. Many of them may not require an Internet connection, but those that do can retrieve real-time data, store user content. This is highly effective and meets all smart parks criteria.

- Digital sensors can record, store, and wirelessly transmit data about light intensity, temperature, moisture, air and water quality, resource consumption, motion, and other factors.

\subsubsection{Landscape elements}

There are many digital technologies used in landscape elements within smart parks that help to achieve all the value criteria of smart parks., as follows:[2]

Automatic lawn mowers: It is an electric machine, that runs on electricity instead of fuel, does not emit air pollutants. By reducing carbon dioxide emission, it can reduce the need of human maintenance Fig. (1).

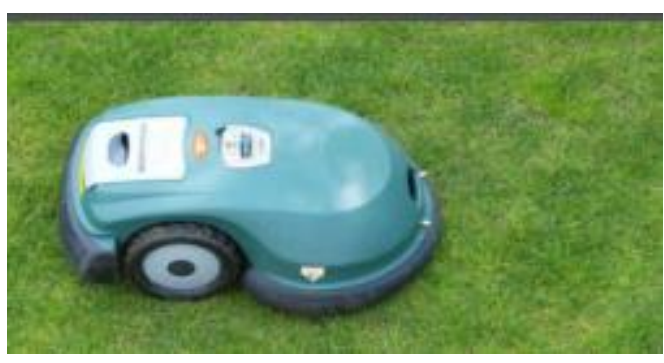

Fig. 1 - Automatic lawn mowers

Near-infrared photography: The photos can be taken with a near-infrared camera or by purchasing a kit to alter a traditional digital camera. Post-processing 
software can be used on the photograph to gain insight on the plant's health. This can be used to alert mangers to existing or potential problems in tree health, allowing staff to take action to prevent trees from falling Fig. (2).

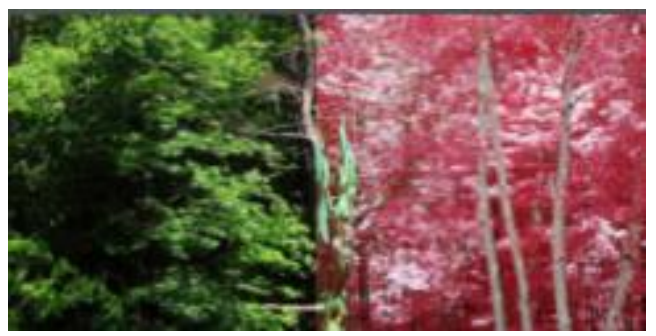

Fig. 2 - Typical photo, left, compared with nearinfrared version, right, which can help determine health of trees

Green roofs \& walls: It is one of the techniques of modern landscape in smart parks, it is the lightest type and requires the least amount of maintenance and no permanent irrigation system. Green walls may be called substrate-based, as it uses lightweight containers full of soil or other growing substrates attached to the wall and incorporate irrigation and water drainage systems [9] Fig. (3).

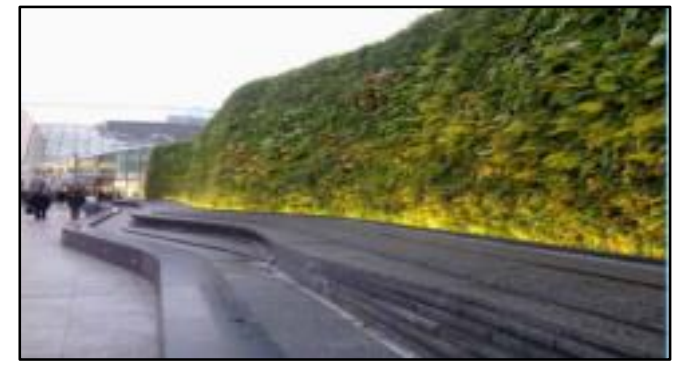

Fig. 3 - Green wall

Air-pruning plant containers: Air-pruning plant containers are temporary plant holders established to encourage healthy root growth specially during stressful weather or drought events.

Vibrating pollinators: There are battery-operated tools that vibrate near the same frequency as pollinators' wings to induce plants to release pollen, so they can be pollinated buy human hand Fig. (4).

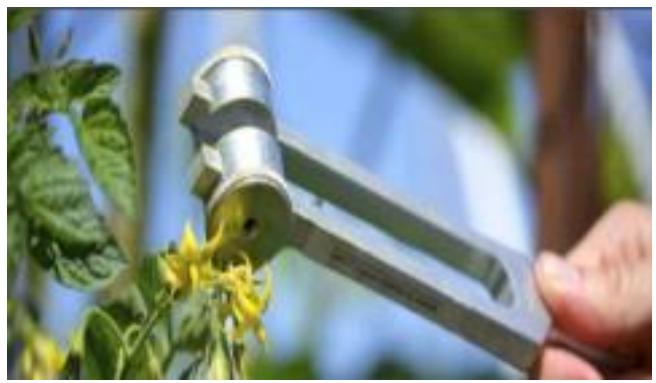

Fig. 4 - Parks with edible gardens can use vibrating pollinators as a strategy to increase crop yield.

Smart irrigation (Smart water controllers): They are also known as timers. They digitally manage watering patterns and adjust water usage as irrigation is responsible for approximately $70 \%$ of freshwater use worldwide .

Smart irrigation (Low-pressure and rotating sprinklers): Rotating sprinkler heads ensure $360^{\circ}$ coverage around the sprinkler, while using a lowpressure to allow water to penetrate the ground instead of being carried away by wind [10] Fig. (5).

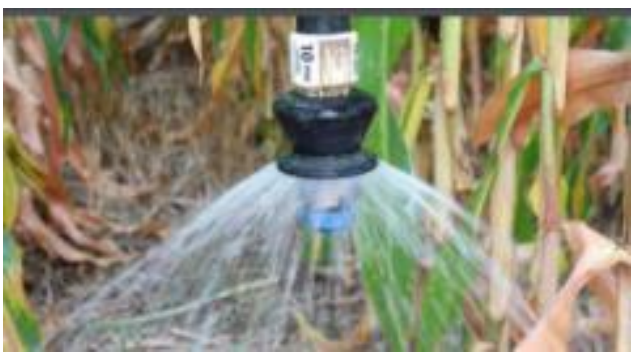

Fig. 5 - Low-pressure and rotating sprinklers

Smart irrigation (Subsurface drip irrigation- SDI): Although, it has been used for several decades, recent irrigation's innovations, such as smart water controllers and graywater recycling technology, have increased their viability for use in parks Fig. (6).

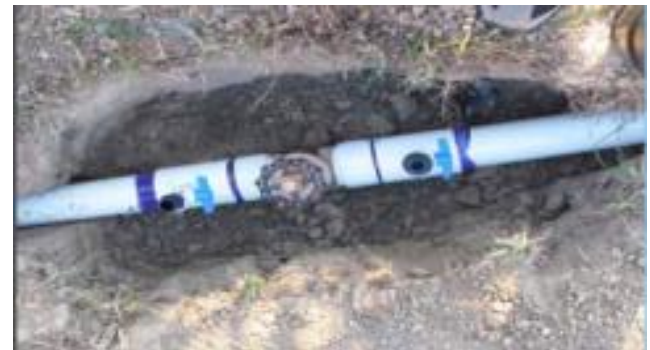

Fig. 6 - Subsurface drip irrigation (SDI)

Smart irrigation (Smart water metering): Smart water meters identify areas of high-water consumption, allowing the manager to pinpoint opportunities to conserve water and prevent water flooding.

Smart irrigation (Graywater recycling): It is the process of recycling wastewater that has been used once in showers or sinks. The recycled water can contain moderate amounts of nitrogen, phosphorous, and potassium that are essential for plant health and act as natural fertilizers and reduce the need of use artificial fertilizers [11].

Urban furniture and amenities: include structures and furniture's that visitors use in smart parks, such 
as, smart benches, solar shade structures, solarpowered trash compactors, restroom occupancy sensors, smart water fountains, digital signs, automatic bicycle and pedestrian counters Fig. (7).

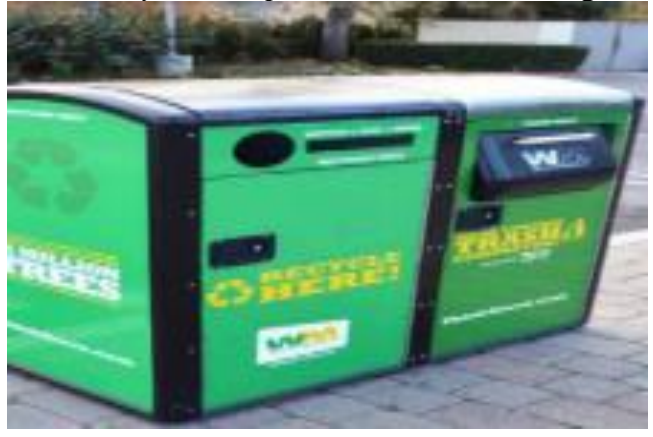

Fig. 7 - Urban furniture and amenities

Smart lighting: Lighting choices play a role in addressing light pollution, which is the excessive use of inappropriate artificial light that can cause adverse consequences for humans, wildlife and the climate. There are five technologies that can be used to improve lighting equipment in smart parks.

Smart lighting (Motion-activated sensors), It can be used anywhere in parks to illuminate areas in use. Motion sensors can also help reduce light pollution by turning off the lights when they are no longer required.

Smart lighting (LEDs and fiber optics as art), LEDs (light emitting diodes) are semi-conductors that emit light when connected to an electric current. Fiber optics are flexible fibers of glass or other transparent solids used to transmit light. They are a technological advancement and cause there to be safer and more reliable data transmission. This technology can be computerized and variably shaped to create unique visual displays Fig. (8).

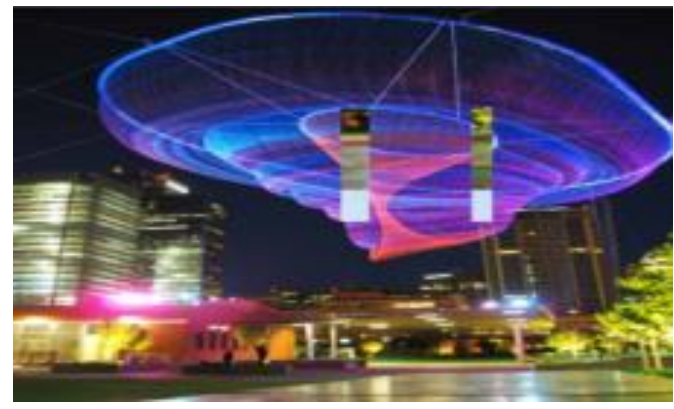

Fig. 8 - LEDs and fiber optics as art

Smart lighting (Off-grid light fixtures): They are independent of the local power grids. And get their energy sources via renewable energy generating devices, including solar panels or wind turbines
Fig. (9).

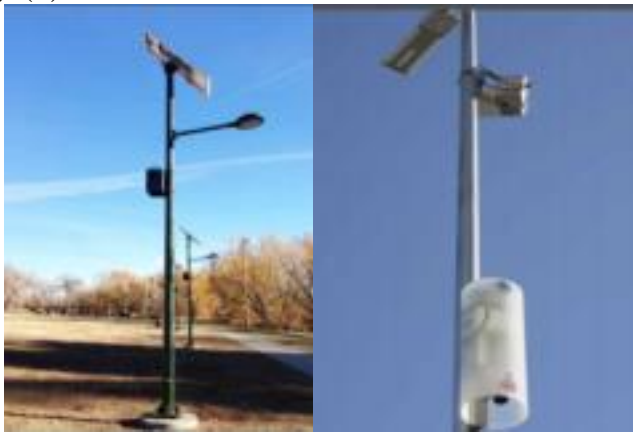

Fig. 9 - Off-grid light fixtures and digital addition to LED fixtures

Smart lighting (Digital additions to LED fixtures): These digital technologies can record and track light, noise, weather, air quality, pedestrian, and vehicle traffic data. It helps increase the quality of the internet connectivity. They can be added to LED fixtures using digital additions

Lighting shields: It may be used on existing fixtures in all areas of the park, by placing a cover around each light source. It can be an important part of a strategy to reduce and control light pollution.

\subsubsection{Activity spaces}

Designing spaces to use technology to achieve all the value criteria of smart parks and create a unique space for music, dancing, and community interaction that can attract visitors and may especially appeal to teenagers. Technologies exist to create more accessible activity spaces, including new materials, different design of spaces, maintenance techniques, equipment designs, and Wi-Fi capabilities. There are six technologies that park managers and designers can utilize to enhance activity spaces, as shown[2] :

Interactive play structures: There are similar in structure to traditional play structures but have an integrated computer games system that visitors can interact with virtually. The structures can also gather visitor data and are connected to the Internet to allow for remote management .

High-performance track surfaces: They are weatherresistant rubber running tracks made of two layers to provide efficient traction and absorption of shocks. High-performance tracks can increase performance for athletes, are easier on the joints, and it can attract more park visitors and encourage physical activity.

Pool ozonation: It is a water filtration technique with two components: ozone generation and ozone management. Ozone generation creates ozone particles in the water that removes organic and inorganic compounds and sanitizes water in a way that is similar to chlorine, but without chlorine's negative health effects of eye and skin irritation [12]. 
Energy-generating exercise equipment: The equipment, which is similar to machines found in gyms, these machines come in indoor or outdoor varieties. Outdoor exercise equipment's are designed for durability and low maintenance. Also, these machines have a benefit that normal gym machines do not possess, which is that they are capable of turning the person's kinetic energy to chemical energy and potential energy that can be later on used as a clean source of energy.

Outdoor DJ booths: Outdoor DJ booths are structures used to manipulate pre-loaded beats or music from mobile phones or laptops. The booths can be charged by renewable energy.

Hard-surface testing equipment: Hard-surface testing equipment is used as a practical way to test the safety of hard surfaces under playgrounds instead of using an "eyeball test" to assess surfaces. Hardsurface testing equipment uses electronic sensors to mimic a child's head to provide quickly accessible data on impact, velocity, and potential for head injury. This is used to reduce the chance of child injuries while playing and improving safety.

\section{ANALYTICAL STUDIES}

Through the comparative analytical study, an analysis is conducted on some of the most innovative smart parks in the world both globally and regionally to extract suitable criteria for measuring the performance of smart parks based on what was reviewed in the theoretical study, and what was actually applied in the implementation of these smart parks. These gardens are "Gardens by the Bay" Singapore, "Haidian park" China, "Sky garden" London, "AL Mamzar Park" The United Arab Emirates, "AL Janbiyah Eco-Environmental Garden" Bahrain and "Dubai Miracle Garden" The United Arab Emirates.

\subsection{Global parks}

\subsection{1 "Gardens by the Bay" Singapore}

It is a nature reserve extending over 100 hectares (250 acres) of reclaimed land in downtown Singapore. It consists of three waterfront gardens: Southern Gulf Park, East Gulf Park and Central Gulf Park. The largest of these parks is the Southern Gulf Park, which occupies an area of 54 hectares. The Gulf Gardens are part of the Singapore government's strategy to transform Singapore from a garden city into a city in a park. The innovative services that the park includes:

Save energy: It includes specially selected glass panels that minimize solar heat gain, and a cooling process that dehumidifies the air using a liquid desiccant system to save the energy used. This method of energy conservation is an efficient technology that results in up to 30 percent of electricity savings .

Sustainable energy: The garden's dependency on the power grid is also reduced through the great usage of solar panels installed on some of its tower-like super tree structures. The gardens themselves generate up to 8 percent of its electricity need [13] .

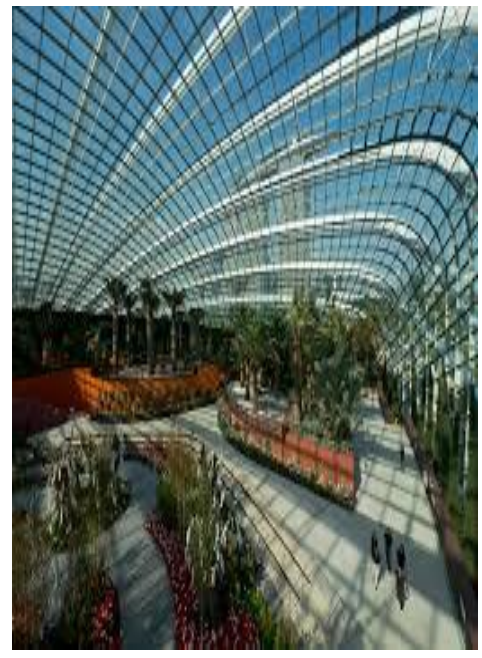

Fig. 10 - flower dome

Smart environment: Gardens by the Bay have applied the principles of environmental sustainability. Much effort was made to plan and design for sustainable cycles in energy and water.

Smart water: The Gardens lake incorporates key ecological processes and functions as a living system. It acts as a natural filtration system for the excess water from the Gardens catchment and provides aquatic habitats for biodiversity such as fishes and dragonflies.

Smart irrigation: The Water run-off from within the Gardens is captured by the inner lake system and cleansed by the means of aquatic plants before being discharged into the reservoir. Naturally, the treated water from the lake system is also used in the built-in irrigation system for the Gardens .

Smart planting / Save energy: The air in Flower Dome is de-humidified by liquid desiccant (drying agent) before it is cooled. This is done to reduce the amount of energy required in the cooling process [14]. Also, this desiccant is recycled using the waste heat from the burning of the biomass Fig .(10) .

Smart Maintenance an aquatic ecosystem: Habitats for fish are created within the lake system by maintaining a diversity of aquatic plants, good water circulation, and aeration. This keeps current and potential problems on the park's radar such as mosquito breeding Fig. (11). 


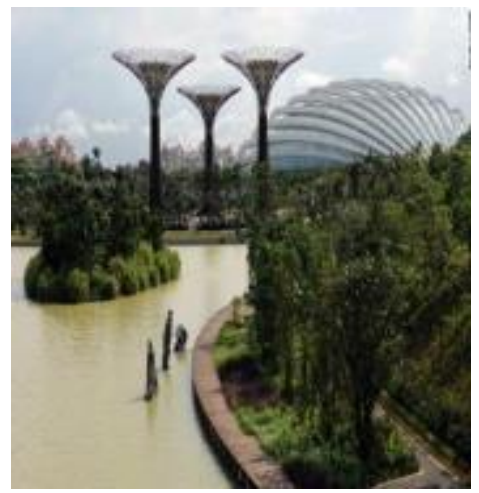

Fig. 11 - garden's lake

Conclusions: The value criteria applied in "Gardens by the Bay" Singapore and its indicators include

- Smart environment: considered an example of sustainable environment projects. And it works to generate vital energy and produce clean energy.

- Smart governance: by generating electricity from special solar panel, as well as the fact that all maintenance is immediately uploaded to the park's database.

- Smart agriculture: Equipped with an integrated system that allows it to reuse rainwater after storing it, and using treated water.

\subsection{2 "Haidian park" China}

Haidian Park has become one of the country's foremost technologically advanced communities. The parks history traces to its close proximity to China's most prestigious technology universities and research institutions [15]. The innovative services that the park includes:

Smart mobility: The park has autonomous shuttle buses, smart walkways tracking people's steps using facial recognition. The park has a digital leaderboard of sorts. It is part of an 'intelligent' jogging track that runs along the park. Stand in front of the board, get your picture taken, sync with your phone, and run on the track. Cameras will scan the run and record details

of your run at the end of a lap that will be displayed . Smart lighting/Smart facilities: Smart lamp posts that can record data, and intelligent pavilions equipped with a conversational assistant between visitors.

Smart environment: The park has virtual reality gear, a walking, talking robot which looks a Star Wars character, and more screens to entertain the visitors or be used as a mean of amusement.

Part of smart city/ Smart technology: The park came after the government's decision to build a "smart city", which welcomed about 1.2 million tourists during the previous year. After running the pilot program, the park is trying to upgrade in order to make life easier and more luxurious through applications of artificial intelligence.

Digital technologies and application: Geographic information systems (GIS) use digital software to store, manipulate, analyze, and present geographical data by determining roads and parking availability. The park uses its digital sensors to record, store, and wirelessly transmit information.

Smart sounds: When a visitor inquiries about anything, artificial intelligence devices will answer, which helps promote the visitors to inquire about information, service life, travel conditions, and the acquisition of information and other functions

Fig. (12).

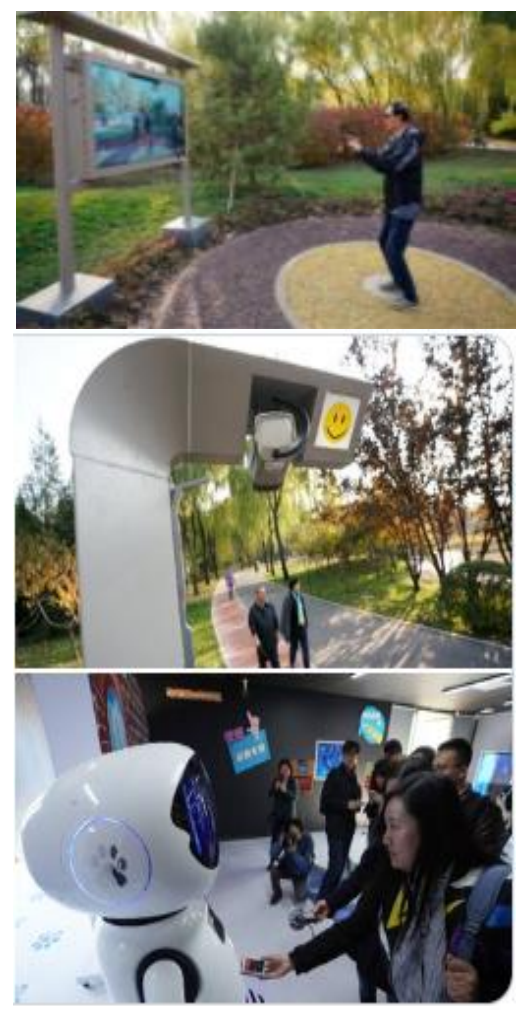

Fig. 12 - digital technologies and application

Conclusions: The Value criteria applied in "Haidian park" China and its indicators include

- Smart mobility: By using autonomous shuttle buses and smart walkways tracking people's steps using facial recognition.

- Smart environment: It is designed to be part of a smart city. It is also using different applications of artificial intelligence to help aid the visitors and answer all their inquiries, as well as being a somewhat form of entertainment for them.

- Smart Governance: Take full control of the audio and video surveillance of the park and help visitors 
to gain information about various roads to hike using its internet database.

\subsection{3 "Sky garden" London}

Sky Garden is London's most elevated public garden, a social space with 360-degree views of the city's iconic skyline. A park inside a skyscraper in the British capital, London. Although it is a biomass of green trees on the 34th to 37th floors of the building, these floors are equipped to be a smart garden by using noise control systems Fig. (13). Many of its innovative features include:

Smart planting: It controls the air quality of the atmosphere of the crops, to ensure the ideal conditions for the plant to grow and produce the greatest yield. It is also home to drought-resistant flowering plants .

Smart energy and smart governance: The park uses several renewable energy technologies that produce energy that doesn't produce carbon emissions and focuses on producing clean energy that doesn't pollute the environment .

Smart maintenance: By maintaining a good indoor garden all year-round using plant sensors and their vital functions, to monitor for any existing or potential diseases that could affect the plants health.

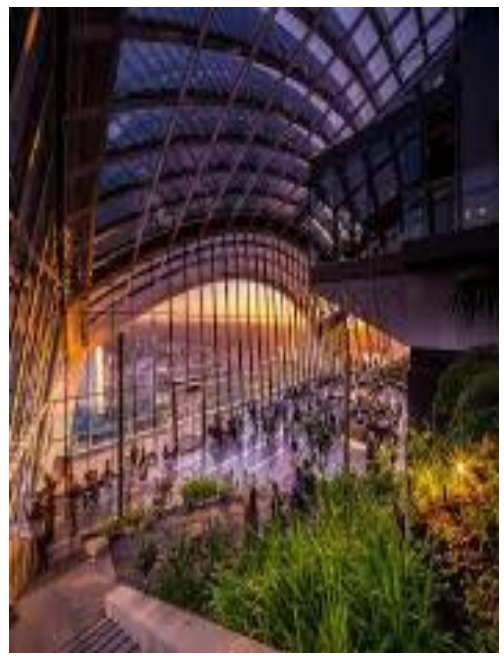

Fig. 13 - Sky garden "London”

\subsection{Regional parks}

\subsection{1"AL Mamzar Park" The United Arab}

\section{Emirates}

Al Mamzar Park is located on the banks of the Gulf on the western side of the beaches of Dubai and the beaches of the park adjacent to the shores of the Emirate of Sharjah. It covers an area of 99 hectares. The park includes many innovative services such as: Smart Bands: Waterproof smart watch with GPS are provided to help families track their children inside the park[16]. Fig. (14)

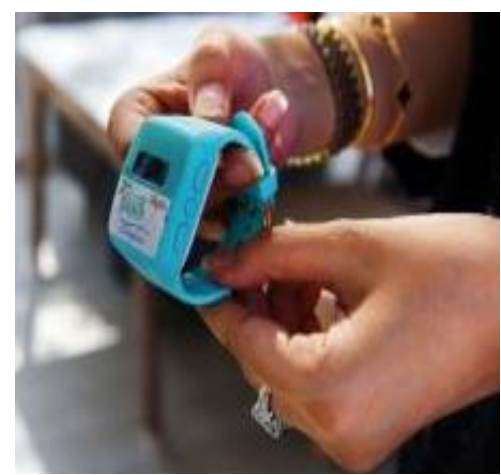

Fig. 14 - Smart band

Smart Oasis: It has two smart oasis hubs by the beach to provide shade and a system to harvest humid air and convert it into drinking water by using solar power. The Smart Oasis can produce $90 \mathrm{~m} 3$ of drinking water every day. It also provides a charging area for phones and using tracking technology caretakers can track the phones to ensure their safety Fig. (15).

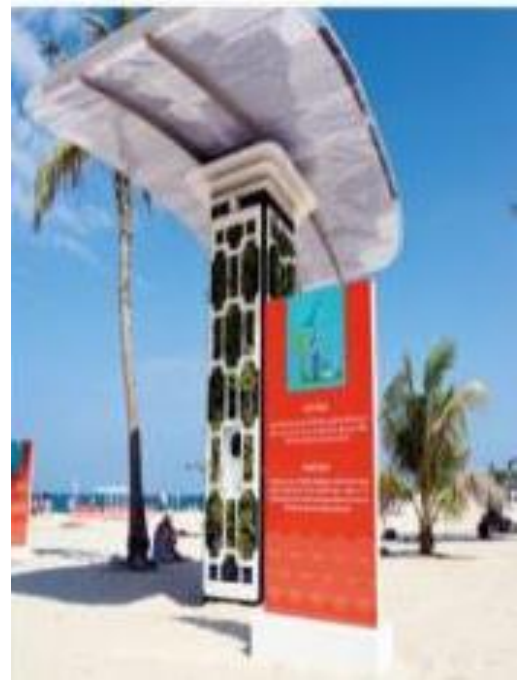

Fig. 15 - Smart Oasis

Smart Scanning: Used to monitor the plants and trees. Plant classification and detection of illness and diseases will be done using aerial imagery analysis, thermal maps, and carbon emission ratios. Fig. (16).

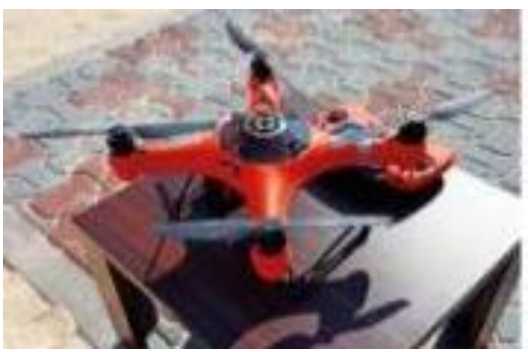

Fig. 16 - Smart drones 
Smart Containers: Send out alerts when the container is full, so that someone can clear it .

Smart Rescue: The municipality has recently launched a smart rescue system using drones that dispatch lifebuoy rings to rescue swimmers from drowning in the Gulf .

Smart Benches, Bands: More than 10 solar-powered smart benches provide free internet and wireless charging services for mobile phones. In order to keep the phone charging, simply place it on the bench.

Smart Palms: They provide free $\mathrm{Wi}-\mathrm{Fi}$ and charging stations are also already available in the park which are considered part of the advancement of digital technology .

Telephone app.: Park visitors can use the app to take a virtual tour of the facilities, and book their favorite chalet, grill area, and sports areas before going there themselves. There is also a new virtual learning center also in the park to provide education and fun simultaneously.

Virtual reality experience: The experience of planting vegetables and fruit trees for children is provided, while teaching them about the environment as well.

Smart paints: The amphitheater area has been painted with smart paint that reduces air pollution by absorbing carbon dioxide.

Conclusions: The value criteria applied in $A L$ Mamzar Park and its indicators include

- Smart individuals: Using the smart bracelet service, it is a way that allows parents to track the movements of their children.

- Smart rescue: which works to save the visitors from drowning with a drone.

- Smart facilities: to allow visitors to charge their devices electronically from smart seats inside the park. And including solar powered seats and lighting poles.

- Smart Environment: By serving the smart board, it transforms the humidity of the atmosphere into fresh water.

- Smart Governance: Through the smart scanning service that you it uses to create a database and detect diseases, classify plants, and carbon emission ratios.

3.2.2 "AL Janbiyah Eco-Environmental Garden" AL Janbiyah Eco-Environmental Garden is the first park in the Kingdom of Bahrain to be completely powered by renewable energy; using solely solar and wind energy. It is considered a turning point for the development of the rest of the parks in the Kingdom. The park includes many innovative features including:
Clean energy: By using solar panels and energy generating fans to operate the park in order to reduce pressure on the government grid system hence reducing the amount of non-renewable energy used. The garden contains 23 panels for solar energy at a rate of 250 watts and contains two fans to generate electricity from wind at a rate of 150 watts from each fan, this produces sufficient energy to run the parks [17] .

Smart lighting: Reduces lighting consumption of electricity by replacing traditional high-energy lighting with low efficiency with low-consumption lamps (LEDs) that have a much higher efficiency and longevity and achieving significant electricity savings by up to $64 \%$ and reduces the costs .

Smart planting \& smart environment: It uses waste recycling, which includes the usage of organic garden waste resulting from cutting and pruning crops, in addition to food waste from visitors and turns them into organic agricultural fertilizers, which contributes to the disposal of waste and the provision of fertilizers while maintaining a low cost.

Smart Maintenance: It sends all its waste to recycling factories, to renew the usage of the waste resources.

Cultural identity: As this element includes the recycling and the usage of large agricultural wastes and is used in the execution different forms of garden furniture or shaded places inspired by the Bahraini heritage (wooden artwork) Fig. (17).

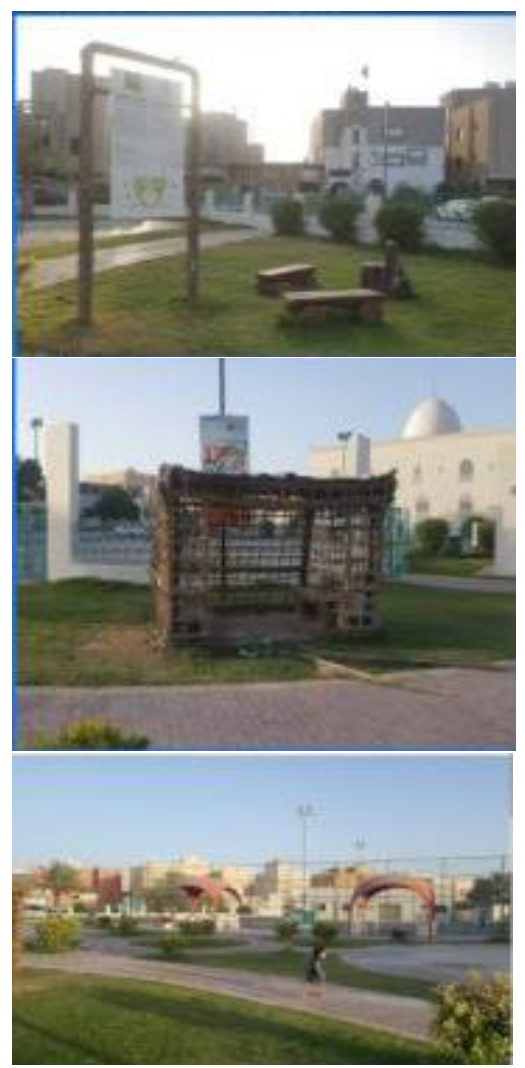

ERJ, Menoufia University, Vol. 43, No. 3, July 2020 
Fig. 17 - AL Janbiyah Eco-Environmental Garden

Smart facilities: By adding specified seats and pedestrian path for visitors with special needs. It also has smart seats that allow for the wireless charging of the visitors phones, so long as they are seated on them.

Smart spaces: The park contains free Wi-Fi for visitors inside all the different areas of the garden.

Conclusions: The value criteria applied in $A L$ Janbiyah Eco-Environmental Garden and its indicators include

- Smart facilities: To allow visitors to charge their devices electronically from smart seats inside the park.

- Smart environment: By providing an environment with suitable technology that works with clean renewable energy.

- Smart Governance \& maintenance: By sending all kinds of waste to recycling factories, and the entire facility is controlled and monitored through the Internet.

- Smart agriculture: By recycling agricultural residues and wastes to form organic agricultural fertilizers.

\subsection{3 "Dubai Miracle Garden"The United Arab Emirates}

The garden was launched on Valentine's Day in 2013. The garden occupies over 72,000 square meters [18], making it the world's largest natural flower garden featuring over 50 million flowers. Dubai Miracle Garden was then carried out and completed by Akar Landscaping and Agriculture Company at a cost of around \$11 million (AED 40 million) Fig.(18) .

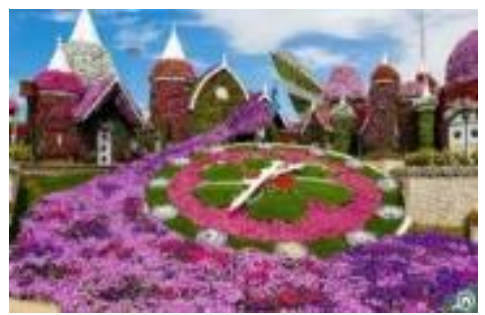

Fig. 18 - Flower clock "15 meters high"

The innovative services that the park include :

Smart irrigation (Graywater recycling): Dubai has no sewer system. The water is then cleaned and processed. Dubai municipality retreats the grey water of the city and sends it directly to the garden. The garden again re-filters the water and converts it to a very high-quality water for its usage at the garden

Smart irrigation (Smart water metering): Smart water meters identify areas of high-water consumption, and evenly regulates the usage of the water, as the plants are only watered after the closing hours at night.

Smart environment: It is the first in the region to open an indoor butterfly garden and sanctuary that houses over 15,000 butterflies, therefore making it the world's largest butterfly garden.

Green roofs \& walls: It is one of the techniques of modern landscape in smart parks. As part of a licensing deal between the Dubai Miracle Garden and The Walt Disney Company, a topiary of Mickey Mouse was unveiled in 2018 [19]. The Dubai Miracle garden was also declared as the world's largest vertical garden, leading the green walls development notion. Currently, an Airbus A380 flower structure in the garden is listed by Guinness World Records as the biggest flower structure in the world Fig. $(19,20)$.

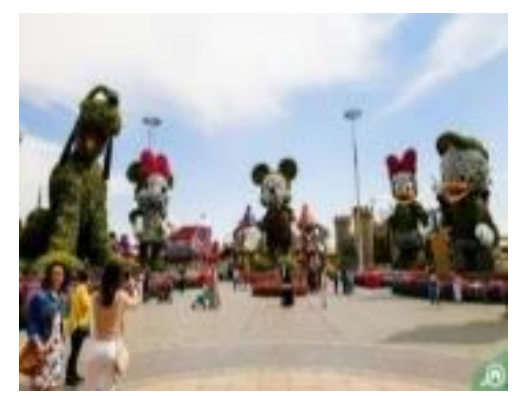

Fig. 19 - Mickey Mouse anthropomorphic

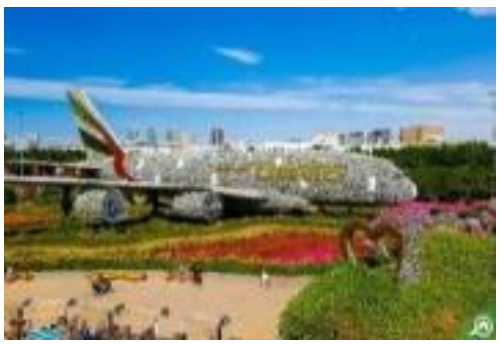

Fig. 20 - The model of the Emirates Airbus A380

Conclusions: The value criteria applied in Dubai Miracle Garden and its indicators include

- Smart irrigation: using gray water to irrigate the garden completely after it closes its doors in the evening.

- Smart planting: Through the work of vertical Agriculture work models of Disney and Airbus aircraft have been made.

- Smart environment: Has the world's largest indoor butterfly garden and sanctuary. 


\subsection{The criteria and indicators that were derived from the analysis of smart gardens both globally and regionally}

Through the analysis of several gardens both regionally and regionally, we have acquired a criteria that is considered to be the foundation for evaluating smart parks, also detecting several characteristics that are present and used as the indicators for that criteria, Table (1).

Table 1- The criteria and indicators that were derived from the analysis of smart gardens

\begin{tabular}{|c|c|}
\hline Criteria & Indicators \\
\hline $\begin{array}{c}\text { Smart } \\
\text { planting }\end{array}$ & $\begin{array}{l}\text { Automatic irrigation, smart devices, } \\
\text { automatic lawn tractors, interaction with } \\
\text { rainwater, follow up the needs of plant } \\
\text { growth and Weather prediction. }\end{array}$ \\
\hline $\begin{array}{c}\text { Smart } \\
\text { governance }\end{array}$ & $\begin{array}{l}\text { Using smart devices (free Wi-Fi - using } \\
\text { the Internet), geographical Information } \\
\text { System (GIS), Carbon emission ratios and } \\
\text { intelligent scanning techniques by } \\
\text { classifying plants, detecting diseases, trees } \\
\text { and extracting vital indicators. }\end{array}$ \\
\hline $\begin{array}{c}\text { Smart } \\
\text { environment }\end{array}$ & $\begin{array}{l}\text { Clean energy production, interaction with } \\
\text { rainwater, dependency on clean energy to } \\
\text { run the park and reduce material } \\
\text { consumption, weather forecast, control the } \\
\text { internal and external environment and } \\
\text { Carbon emissions control. }\end{array}$ \\
\hline Smart people & $\begin{array}{l}\text { Convert the movement to energy, free use } \\
\text { of Wi-Fi and securing individuals with a } \\
\text { smart bracelet. }\end{array}$ \\
\hline $\begin{array}{c}\text { Smart } \\
\text { maintenance }\end{array}$ & $\begin{array}{l}\text { Intelligent maintenance control units, } \\
\text { confronting risks, crises, and disasters, } \\
\text { improved operating efficiencies, fire alarm } \\
\text { systems and intelligent scanning } \\
\text { techniques. }\end{array}$ \\
\hline $\begin{array}{c}\text { Intelligent } \\
\text { mobility }\end{array}$ & $\begin{array}{l}\text { Services for people with special needs, } \\
\text { traffic and walking paths and smart } \\
\text { parking. }\end{array}$ \\
\hline Smart control & $\begin{array}{l}\text { Smart robots and artificial intelligence } \\
\text { used for aiding and helping visitors. As } \\
\text { well as the usage of internet-based } \\
\text { databases and uploading data to manage } \\
\text { the park and maintain security. }\end{array}$ \\
\hline
\end{tabular}

\section{Dissections and Results}

Using smart park criteria and indicators, we will propose a model for measuring the performance of smart public parks and measuring the performance of traditional parks and their potential to be turned into smart public parks .

The calculation of the relative weight of each component of the Key Performance Indicators (KPIs) is done by calculating the indicator achievements in each of the applied study parks and awarding (0) which represents [non-verification> 50\%], and (1) which represents [verification $<50 \%$ ], for each KPI the repetition was calculated by adding the score achieved in all parks. The weighing \% was then estimated by dividing the total score of each KPI on the total repetition for all KPIs, Table (2).

Applying the proposed model with its main criteria and performance indicators on Al-Azhar Park in Cairo. By monitoring and summing the relative weights of all KPIs, the performance of Al-Azhar Park as a traditional public park was evaluated. On the other hand, identifying indicators that need to be assessed to turn it into a smart park was concluded, Table (3).

\section{Conclusions}

Through the theoretical and analytical study of the research, the researcher prepared a proposed model for measuring the performance of smart parks, the model included (8) main criteria, (25) sub criteria, (84) key performance indicators (KPIs).

The relative weight of each indicator was determined through the analytical studies carried out on six global and regional parks, which totaled to a $100 \%$.

The proposed model was also applied to Al-Azhar Park, Cairo, to measure its performance as a public park and it was found that it achieves only about 50\% of the criteria and indicators of smart parks. The deficiencies could be identified through indicators in which the park scored 0 , and therefore these indicators are evaluated and improved using the smart governance to improve the performance of this park and turn it into a smart park. 
Table (2) Reference frame for smart public parks and the relative weight of Key Performance Indicators (KPIs)

\begin{tabular}{|c|c|c|c|c|c|c|c|c|c|c|}
\hline \multirow[b]{2}{*}{ 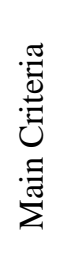 } & \multirow[b]{2}{*}{ 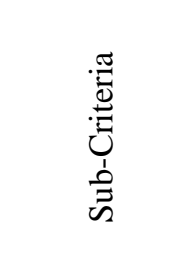 } & \multirow[b]{2}{*}{$\begin{array}{l}\text { Key Performance } \\
\text { Indicators (KPIs) }\end{array}$} & \multicolumn{6}{|c|}{ Regional\& Global parks } & \multirow[b]{2}{*}{$\begin{array}{l}\stackrel{0}{0} \\
\stackrel{0}{0} \\
\stackrel{0}{2} \\
\simeq\end{array}$} & \multirow[b]{2}{*}{$\begin{array}{l}00 \\
.00 \\
.00 \\
.00 \\
30 \\
30\end{array}$} \\
\hline & & & 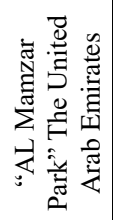 & 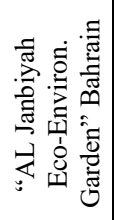 & 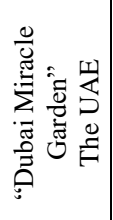 & 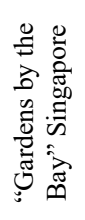 & 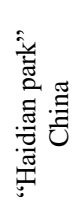 & 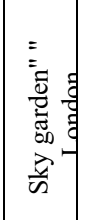 & & \\
\hline \multirow{10}{*}{ 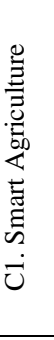 } & \multirow{5}{*}{$\begin{array}{c}\text { C1-1 } \\
\text { Landscape } \\
\text { (SOFTSCAPE) }\end{array}$} & Automatic lawn mowers & 1 & 0 & 1 & 1 & 1 & 0 & 4 & 1.12 \\
\hline & & Near-infrared photography & 1 & 0 & 1 & 1 & 1 & 0 & 4 & 1.12 \\
\hline & & Green roofs \& walls & 0 & 0 & 1 & 0 & 1 & 1 & 3 & 0.84 \\
\hline & & Air-pruning plant containers & 0 & 0 & 1 & 1 & 1 & 0 & 3 & 0.84 \\
\hline & & Vibrating pollinators & 0 & 0 & 0 & 1 & 1 & 0 & 2 & 0.56 \\
\hline & \multirow{5}{*}{$\begin{array}{l}\mathrm{C} 1-2 \\
\text { Irrigation }\end{array}$} & Smart water controllers & 1 & 1 & 1 & 1 & 1 & 1 & 6 & 1.69 \\
\hline & & Low-pressure and rotating & 1 & 1 & 1 & 1 & 1 & 1 & 6 & 1.69 \\
\hline & & Subsurface drip irrigation- SDI & 1 & 1 & 1 & 1 & 1 & 1 & 6 & 1.69 \\
\hline & & Smart water metering & 1 & 1 & 1 & 1 & 1 & 1 & 6 & 1.69 \\
\hline & & Graywater recycling & 0 & 0 & 1 & 1 & 0 & 0 & 2 & 0.56 \\
\hline \multirow{10}{*}{ 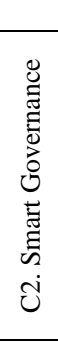 } & & & & & & & & Total & 42 & 11.8 \\
\hline & \multirow{4}{*}{$\begin{array}{c}\text { C2-1 } \\
\text { Digitalis }\end{array}$} & WI-FI & 1 & 1 & 1 & 1 & 1 & 1 & 6 & 1.69 \\
\hline & & Geographic Information system & 1 & 0 & 1 & 0 & 1 & 0 & 3 & 0.84 \\
\hline & & Application software & 1 & 0 & 1 & 1 & 1 & 1 & 5 & 1.40 \\
\hline & & Digital sensors & 0 & 0 & 1 & 1 & 1 & 0 & 3 & 0.84 \\
\hline & \multirow{2}{*}{$\begin{array}{l}\text { C2-2: Smart } \\
\text { Control }\end{array}$} & Underground rainwater storage basins & 0 & 0 & 1 & 1 & 0 & 0 & 2 & 0.56 \\
\hline & & Soil programming and sensitivity & 1 & 0 & 1 & 1 & 0 & 0 & 3 & 0.84 \\
\hline & \multirow{3}{*}{$\begin{array}{l}\text { C2-3: Smart } \\
\text { Management }\end{array}$} & Smart reservation & 1 & 0 & 1 & 1 & 1 & 0 & 4 & 1.12 \\
\hline & & Electronic payment & 1 & 0 & 1 & 1 & 1 & 0 & 4 & 1.12 \\
\hline & & Intelligent management system & 1 & 0 & 1 & 1 & 1 & 1 & 5 & 1.40 \\
\hline \multirow{14}{*}{ 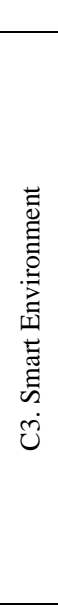 } & & & & & & & & Total & 35 & 9.81 \\
\hline & \multirow{4}{*}{$\begin{array}{l}\text { C3-1: Visitors } \\
\text { qualification } \\
\text { Level }\end{array}$} & Clean energy production & 1 & 0 & 1 & 1 & 1 & 1 & 5 & 1.40 \\
\hline & & Weather prediction & 0 & 0 & 1 & 1 & 1 & 1 & 4 & 1.12 \\
\hline & & Carbon emissions control & 1 & 0 & 1 & 0 & 1 & 1 & 4 & 1.12 \\
\hline & & Convert movement into energy & 0 & 0 & 0 & 0 & 1 & 0 & 1 & 0.28 \\
\hline & \multirow{5}{*}{$\begin{array}{l}\text { C3-2: Lifelong } \\
\text { Learning }\end{array}$} & Motion activated lights & 1 & 0 & 1 & 0 & 0 & 0 & 2 & 0.56 \\
\hline & & LEDs and fiber optics as art & 1 & 1 & 1 & 1 & 0 & 0 & 4 & 1.12 \\
\hline & & Off-grid light fixtures & 1 & 0 & 1 & 1 & 1 & 0 & 4 & 1.12 \\
\hline & & Digital additions to LED fixtures & 0 & 0 & 1 & 0 & 1 & 0 & 2 & 0.56 \\
\hline & & Lighting shield & 0 & 0 & 1 & 1 & 0 & 0 & 2 & 0.56 \\
\hline & \multirow{2}{*}{$\begin{array}{l}\text { C3-3:Ethnic } \\
\text { Plurality }\end{array}$} & $\begin{array}{c}\text { Individual efforts to protect the } \\
\text { environment }\end{array}$ & 0 & 1 & 1 & 1 & 1 & 1 & 5 & 1.40 \\
\hline & & $\begin{array}{l}\text { Different opinions about } \\
\text { environmental protection }\end{array}$ & 1 & 1 & 0 & 0 & 1 & 1 & 4 & 1.12 \\
\hline & \multirow{2}{*}{$\begin{array}{l}\text { C3-4: Open } \\
\text { Mindedness }\end{array}$} & $\begin{array}{l}\text { Actual water consumption /relative } \\
\text { consumption to GDP }\end{array}$ & 0 & 0 & 1 & 1 & 1 & 1 & 4 & 1.12 \\
\hline & & $\begin{array}{l}\text { Electricity consumption /relative } \\
\text { consumption to GDP }\end{array}$ & 1 & 1 & 1 & 1 & 1 & 1 & 6 & 1.69 \\
\hline \multirow{12}{*}{ 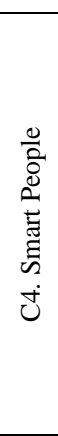 } & & & & & & & & Total & 47 & 13.17 \\
\hline & C4-1 Visitors & Educational level (medium / high) & 1 & 0 & 1 & 1 & 1 & 1 & 5 & 1.40 \\
\hline & Level & Language skills & 1 & 1 & 1 & 1 & 1 & 1 & 5 & 1.40 \\
\hline & & Cognitive perception & 1 & 0 & 1 & 0 & 0 & 1 & 3 & 0.84 \\
\hline & $\begin{array}{l}\text { C-2: Lirelong } \\
\text { Learning }\end{array}$ & Continuous education & 1 & 0 & 1 & 1 & 1 & 1 & 5 & 1.40 \\
\hline & & Cultural awareness & 1 & 1 & 1 & 1 & 1 & 1 & 6 & 1.69 \\
\hline & & Foreign visitors & 1 & 1 & 1 & 1 & 1 & 0 & 5 & 1.40 \\
\hline & $\begin{array}{l}\text { Plurality } \\
\text { Plo }\end{array}$ & Visitors (citizens residing abroad) & 0 & 0 & 0 & 1 & 1 & 0 & 2 & 0.56 \\
\hline & & Local visitors & 1 & 1 & 1 & 1 & 1 & 1 & 6 & 1.69 \\
\hline & & Adopting new ideas & 1 & 1 & 1 & 1 & 1 & 1 & 6 & 1.69 \\
\hline & Mindedness & Contributing to volunteer work & 1 & 0 & 1 & 0 & 1 & 1 & 4 & 1.12 \\
\hline & & Community participation & 1 & 1 & 1 & 1 & 1 & 1 & 6 & 1.69 \\
\hline & & & & & & & & Total & 53 & 14.88 \\
\hline
\end{tabular}


Table (2- continued) Reference frame for smart public parks and the relative weight of Key Performance Indicators

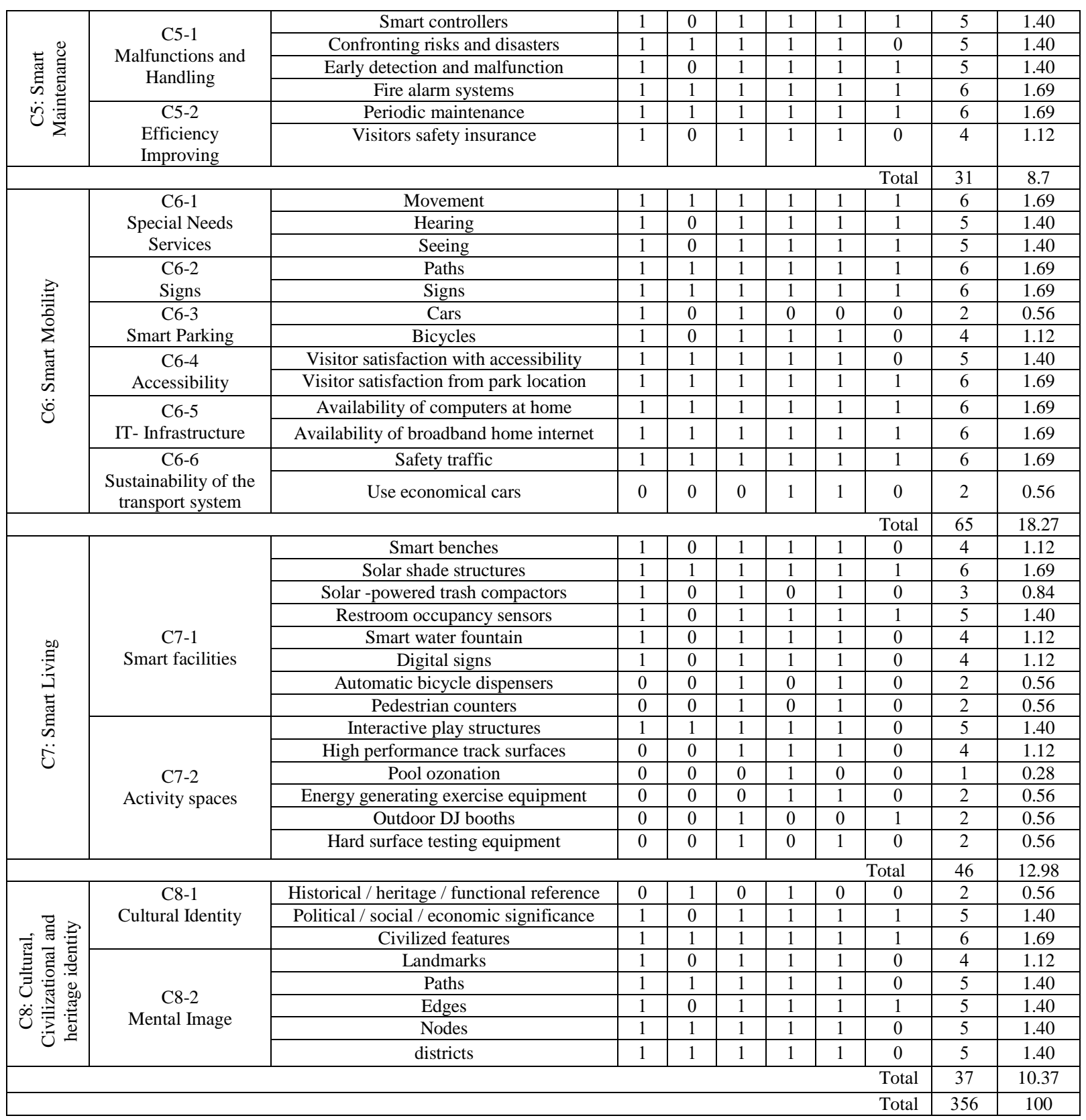


Table (3) Application of the proposed model for assessing smart parks on Al-Azhar Park in Cairo.

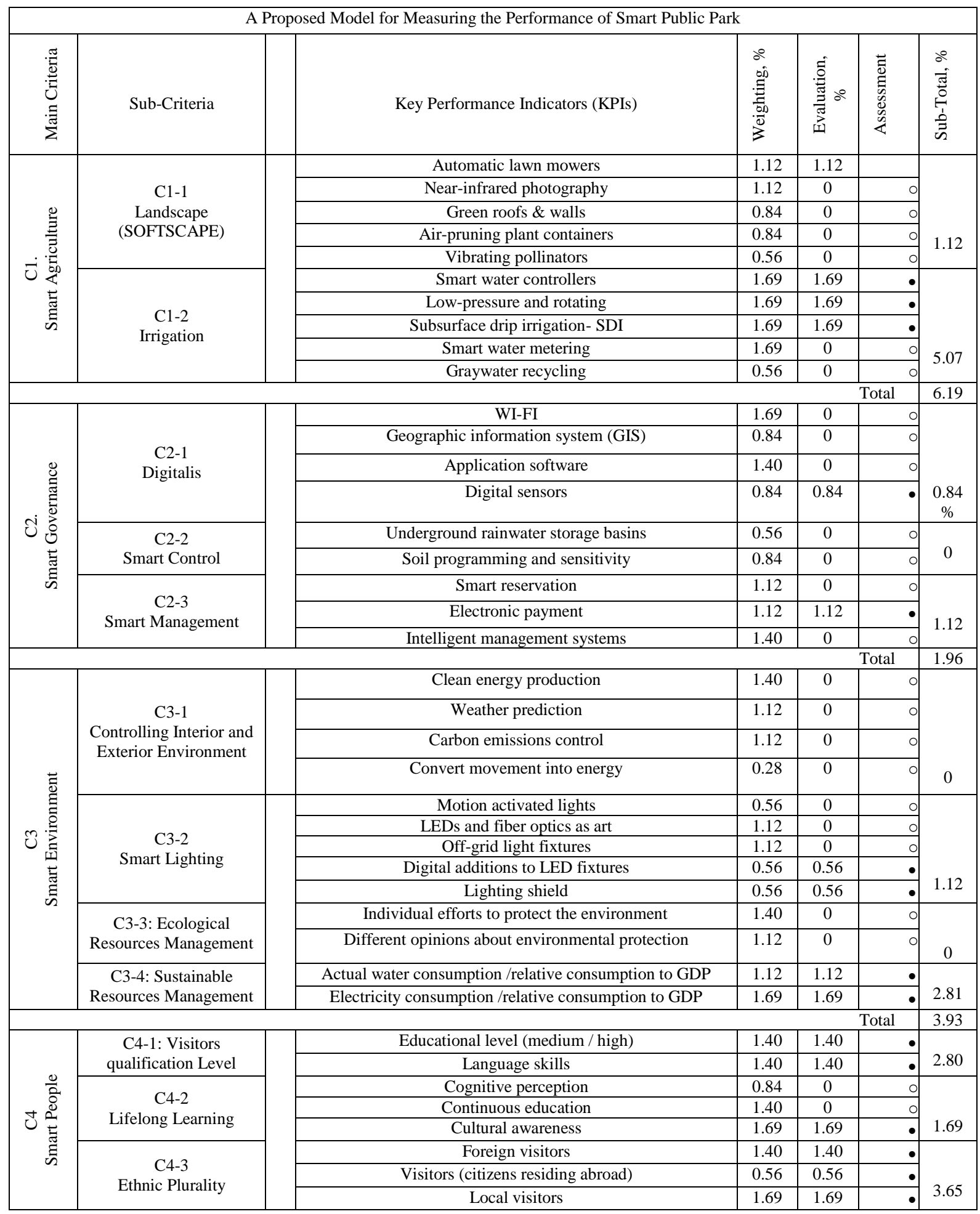


Table (3- continued) Application of the proposed model for assessing smart parks on Al-Azhar Park in Cairo

\begin{tabular}{|c|c|c|c|c|c|c|}
\hline & \multirow{3}{*}{$\begin{array}{c}\text { C4-4 } \\
\text { Open Mindedness }\end{array}$} & Adopting new ideas & 1.69 & 0 & 0 & \multirow{3}{*}{0} \\
\hline & & Contributing to volunteer work & 1.12 & 0 & 0 & \\
\hline & & Community participation & 1.69 & 0 & 0 & \\
\hline \multicolumn{6}{|c|}{ Total } & 8.14 \\
\hline \multirow{6}{*}{ 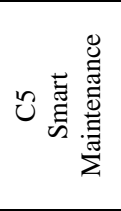 } & \multirow{4}{*}{$\begin{array}{c}\text { C5-1 } \\
\text { Malfunctions and } \\
\text { Handling }\end{array}$} & Smart controllers & 1.40 & 0 & $\circ$ & \multirow{4}{*}{1.69} \\
\hline & & Confronting risks and disasters & 1.40 & 0 & 0 & \\
\hline & & Early detection and malfunction & 1.40 & 0 & 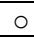 & \\
\hline & & Fire alarm systems & 1.69 & 1.69 & $\bullet$ & \\
\hline & \multirow{2}{*}{$\begin{array}{c}\text { C5-2 } \\
\text { Efficiency Improving } \\
\end{array}$} & Periodic maintenance & 1.69 & 0 & $\mathrm{o}$ & \multirow[b]{2}{*}{1.12} \\
\hline & & Visitors safety insurance & 1.12 & 1.12 & - & \\
\hline & & & & \multicolumn{2}{|c|}{ Total } & 2.81 \\
\hline \multirow{13}{*}{ ৩ } & \multirow{3}{*}{$\begin{array}{c}\text { C6-1 } \\
\text { Special Needs Services }\end{array}$} & Movement & 1.69 & 1.69 & - & \multirow{3}{*}{1.69} \\
\hline & & Hearing & 1.40 & 0 & 0 & \\
\hline & & Seeing & 1.40 & 0 & $\circ$ & \\
\hline & C6-2 & Paths & 1.69 & 1.69 & $\bullet$ & \multirow[b]{2}{*}{3.38} \\
\hline & Signs & Signs & 1.69 & 1.69 & $\bullet$ & \\
\hline & C6-3 & Cars & 0.56 & 0 & $\circ$ & \multirow{2}{*}{0} \\
\hline & Smart Parking & Bicycles & 1.12 & 0 & $\circ$ & \\
\hline & \multirow{2}{*}{$\begin{array}{c}\text { C6-4 } \\
\text { Accessibility } \\
\end{array}$} & Visitor satisfaction with accessibility & 1.40 & 1.40 & - & \multirow{2}{*}{3.09} \\
\hline & & Visitor satisfaction from park location & 1.69 & 1.69 & $\bullet$ & \\
\hline & \multirow{2}{*}{$\begin{array}{c}\text { C6-5 } \\
\text { IT- Infrastructure }\end{array}$} & Availability of computers at home & 1.69 & 1.69 & $\bullet$ & \multirow{2}{*}{1.69} \\
\hline & & Availability of broadband internet in homes & 1.69 & 0 & $\circ$ & \\
\hline & \multirow{2}{*}{$\begin{array}{l}\text { C6-6: Sustainability of } \\
\text { the transport system }\end{array}$} & Safety traffic & 1.69 & 1.69 & $\bullet$ & \\
\hline & & Use economical cars & 0.56 & 0 & o & 1.69 \\
\hline & & & & & & 11.54 \\
\hline & & Smart benches & 1.12 & 0 & $\circ$ & \\
\hline & & Solar shade structures & 1.69 & 1.69 & - & \\
\hline & & Solar -powered trash compactors & 0.84 & 0 & $\circ$ & \\
\hline & C7-1 & Restroom occupancy sensors & 1.40 & 1.40 & - & 421 \\
\hline & Smart facilities & Smart water fountain & 1.12 & 0 & $\circ$ & 4.21 \\
\hline & & Digital signs & 1.12 & 1.12 & $\bullet$ & \\
\hline - 亲 & & Automatic bicycle dispensers & 0.56 & 0 & $\mathrm{o}$ & \\
\hline$O$ & & Pedestrian counters & 0.56 & 0 & $\circ$ & \\
\hline & & Interactive play structures & 1.40 & 0 & $\circ$ & \\
\hline & $\mathrm{C} 7-2$ & High performance track surfaces & 1.12 & 0 & $\circ$ & \\
\hline & Activity spaces & Pool ozonation & 0.28 & 0 & $\circ$ & 056 \\
\hline & & Energy generating exercise equipment & 0.56 & 0 & $\circ$ & 0.56 \\
\hline & & Outdoor DJ booths & 0.56 & 0.56 & $\bullet$ & \\
\hline & & Hard surface testing equipment & 0.56 & 0 & 0 & \\
\hline & & & & & & 4.77 \\
\hline & & Historical / heritage / functional reference & 0.56 & 0.56 & $\bullet$ & \\
\hline 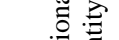 & Cultural Identity & Political / social / economic significance & 1.40 & 1.40 & $\bullet$ & 3.65 \\
\hline 烒 & & Civilized features & 1.69 & 1.69 & $\bullet$ & \\
\hline 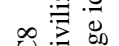 & & Landmarks & 1.12 & 1.12 & $\bullet$ & \\
\hline U己 & & Paths & 1.40 & 1.40 & $\bullet$ & \\
\hline $\bar{\Xi} \Xi$ & $\begin{array}{l}\text { C8-2 } \\
\text { Mental Image }\end{array}$ & Edges & 1.40 & 1.40 & $\bullet$ & 6.72 \\
\hline 严壳 & & Nodes & 1.40 & 1.40 & - & \\
\hline & & districts & 1.40 & 1.40 & $\bullet$ & \\
\hline & & & & & & 10.37 \\
\hline & & & & & & 49.71 \\
\hline The indi & or was not achieved insid & rden, the indicator needed to be assessed & & & $\circ$ & \\
\hline The indi & or was achieved inside th & & & & $\bullet$ & \\
\hline
\end{tabular}




\section{References}

$$
\text { [1] تحمد ابو دهب محمود، "تصميم وتنسيق الحدائق" الدار العربيه للنشر والتوزيع، القاهره طبعه اولى، } 1998 .
$$

[2] SMART Parks"M, “A Toolkit, Luskin Center for Innovation” (UCLA), 2018.

[3] http://site.iugaza.edu.ps/aelastal/files/2010/02/Landscape_Architecture.pdf

[4] Peter Harnik, Jessica Sargent and Jennifer Plowden, "The Economic Benefits of the Public Park and Recreation System in the City of Los Angeles, California, s.l” The Trust for Public Land, 2017.

[5] "National Recreation and Park Association. Safe Routes to Parks: Improving Access to Parks through Walkability" Ashburn, Virginia: NRPA.

[6] Robin Mark and Paolo Perrone, "Trust for Public Land" Interview, 2017.

[7] "What is GIS. Research Guides" University of Wisconsin-Madison Libraries, https://researchguides.library.wisc.edu/c.php?g=178144\&p= 1169699

[8] “A Case Study in Environmental GIS: Light Pollution Mapping” GIS Lounge, December 5, 2014. https://www.gislounge.com/case-studyenvironmental-gis-light-pollution-mapping/

[9] "Green Walls in the UK: Basic Types of Green Wall” Urban Greening, https://www.urbangreening.info/green-wall-types

[10] “Smart Irrigation” City of Santa Barbara, July 2017.

http://www.santabarbaraca.gov/gov/depts/pw/resources/conservation/landscaping/irrigation/default.asp?utm_s ource=PublicWork\&utm_medium=Irrigation\&utm_content=QuickLinks

[11] "Greywater Fact Sheet 4: Keeping Your Plants and Soil Healthy with Greywater" Metropolitan Water Directorate, State of NSW Department of Water and Energy, May 2008.

https://www.metrowater.nsw.gov.au/sites/default/files/publication-documents/Greywater_Factsheet_4_ Keeping_Plants.pdf

[12] Connie Sue Centrella, "Shedding Light on UV and Ozone” poolspanews. Com, Pool and Spa News, May 21, 2014. http://www.poolspanews.com/ facilities/maintenance/shedding-light-on-uv-and-ozone_o

[13] https://www.zdnet.com/article/green-tech-flourishing-at-gardens-by-the-bay/

This information was last checked as of Saturday $9^{\text {th }}$ of April, 2020.

[14] https://www.gardensbythebay.com.sg/en/the-gardens/sustainability-efforts.html

This information was last checked as of Saturday $9^{\text {th }}$ of April, 2020.

[15] IDG China "Haidian Park: The Birthplace of China's Most Innovative and Entrepreneurial Technology Companies, Chinese Silicon Valley Series” CISION PR Newswire, 2015

[16] Sajila Saseendran, “ Dubai’s Al Mamzar Beach Park goes smart, UAE” Huawei AirEngine Wi-Fi 6, 2018. https://gulfnews.com/uae/environment/dubais-al-mamzar-beach-park-goes-smart-1.60338562\#

This information was last checked as of Saturday $4^{\text {th }}$ of April, 2020

[17] http://www.alwasatnews.com/news/1111188.html

This information was last checked as of Saturday $5^{\text {th }}$ of April, 2020

[18] Jay B. Hilotin, “The world's most beautiful garden in Dubai” General, 2013. https://gulfnews.com/general/theworlds-most-beautiful-garden--in-dubai-1.1148995\#

This information was last checked as of Saturday $9^{\text {th }}$ of April, 2020.

[19] Angel Tesorero, "50 million blooms to wow visitors at Dubai Miracle Garden" Khaleej Times, Retrieved 30 October 2018. 